\title{
Study on the Improvement of Physical Education Model Based on Happy Sports Ideas
}

\author{
Liang Chang ${ }^{1}$ \\ ${ }^{1}$ Baicheng Normal University, Baicheng, Jilin, 137000
}

Keywords: Physical Education model; Happy Sports Ideas; improvement method

\begin{abstract}
Happy sports is not only a kind of sports teaching guiding ideology based on humanistic education view, but also a relatively complete teaching methodology and teaching material theory of physical education teaching practice system. While Happy Sports is widely recognized and implemented by our country's general sports educators, this paper comprehensively reviews the origins and development of Happy Sports, the positive impact of Happy Sports on China's sports education reform, and the issues that should be paid attention to when learning and introducing Happy Sports, and has great practical significance for further deepening the reform of sports education, popularizing and implementing Happy Sports.
\end{abstract}

\section{Introduction}

With the continuous deepening of the physical education reform in schools, the research on physical education teaching ideas is very active. The exploration and understanding of happy sports ideas have also become the focus of current research. The concept of modern sports believes that: The most essential motivation for human beings to engage in sports activities is to pursue the endless pleasures embodied in sports. Therefore, sports must take physical fitness and mental health as the main support points, and be integrated with cultural education and entertainment. Sports without pleasure is boring, and it lacks eternal vitality. Happy sports, with music as the core and in the teaching process of fitness, technique and education, can better meet the students' learning requirements and aspirations, effectively cultivate students' interest in sports activities and lifetime sports habits, and develop students' personalities. The improvement of learning enthusiasm for learning is the ideological and theoretical basis for the implementation of the first quality education project in modern school sports. Therefore, it is of great practical significance to discuss and study the deep-seated theory of happy sports.

\section{The Origin, Development and Spread of Happy Sports in China}

Happy Sports originated in Japan and was proposed in the 1979 National Sports Conference in Japan. It is a new idea of physical education that adapts to changes in Japanese society. In the 1980s, it was introduced into the country and it is now developing into a school sports teaching ideology system with the characteristics of the times and international influence. The establishment and development of Japanese happy sports thinking is determined by the values of sports, the requirements of educational reform on teaching objectives, the laws of changes in social history, and the expectations of the country for school sports. It fully shows the construction, development, and social needs of sports science. Coexistence and mutual benefit, advancing with the characteristics of the times. In the 1980s of the 20th century, Japan's school sports, which experienced three historical changes in the period of empiricism, scientism, and physicalism, was influenced by the influence of teacher-led and student-centered scientific humanistic international education, and proposed an internationalization of education concepts and an educational environment. The brand-new educational concept of humanization, flexible education opportunities, collaborative education process, and life-long educational goals combine closely the short-term effects of school sports and long-term interests, and has initiated the systematic project of advocating and implementing lifelong education. Since happiness is highly consistent with lifelong 
sports in terms of education concepts, training goals, and social value orientation, happiness sports have a unique advantage in the reliability and validity of student education, education, and development. Can effectively develop students' personality, cultivate students' sports interest and creativity, and extend the effect of health maintenance and promotion from school sports to lifelong sports. Therefore, Happy Sports was promoted to the frontier of physical education reform, and gradually became a deeply influential and representative physical education teaching idea and teaching model. It also played an increasingly important role in the reform of the physical education and the training of qualified personnel in the new century. effect.

After the founding of New China, China learned and absorbed the Soviet Union's physical education ideology and teaching model. It has long advocated and implemented the sports curriculum theory centering on sports skill learning, and confined school physical education teaching to specialized subjects, academic knowledge, and abstract ideas. , curriculum structuring, method proceduralization, organization standardization, and textbook systemization. Although after 1978, our country restored its original education system, the old education concept has not changed, and the Kelloff-style discipline sports still dominate the school physical education in China. In the teacher's perfusion, filled-in compulsory education, and even rebuking and corporal punishment, more and more students are afraid of sports, school weariness, and evasion of sports. The subjects most loved by students are being turned into students' most in the quirky circle of examination education. Tired subject. What exactly can we do to make the physical education of the sports curriculum new and return to reality, return to the original intention of human beings to establish and develop sports, and make the physical education curriculum truly become a learning education class in practical sense, with this subject, numerous physical education Workers have been struggling to find and seek.

\section{The Positive Influence of Happy Sports on the Reform of Physical Education in China}

First of all, in terms of educational concepts, Happy Sports boldly challenged the traditional concept of physical education, changed to the idea of exam-oriented education to guide physical education, adhered to the educational philosophy and emotional education as a breakthrough, and changed compulsory sports and perfusion sports. Teaching is a joyful, active type of physical education that creates conditions in many ways to meet students' interest and needs in learning. It strives to make students active, active, and healthy. In terms of curriculum objectives, Happy Sports does not deny the authority of education, education, and development. Instead, it emphasizes the relationship between necessary emotional education, love education, beautiful education, and social education as the link between the three major goals. Blend together to more effectively promote the overall function of school sports and achieve a comprehensive improvement in the quality of people. In the structure of the curriculum, traditional disciplinary sports pay too much attention to the discipline structure formed by the discipline's logic and laws, and edit the content of physical education into a combination of various projects, all must be learned and mastered, and there is a unified and standardized requirement. The curriculum structure is standardized, and it is specifically divided into several parts (usually more than three parts), and each part has specific tasks and requirements. The current happy sports reform formulation and stereotyped curriculum structure is a two-way development of the curriculum structure. The learning structure is both dialectical and flexible in the selection and application of dual structures. It not only maintains a certain program structure import. Expand, and there are no fixed rules. In the reform of the syllabus and teaching materials, the current syllabus for physical education and health reflects the combination of theory and practice of happy sports, the combination of humanities and sports, the combination of sports and health care, the combination of fitness and entertainment, and educating The outline compilation principles that combine with the body, combined with unity and flexibility, broke the traditional textbook-based arrangement system and increased the self-cultivation, fitness, guidance, entertainment, games, dance, and meet the students' age characteristics and interests. The teaching content of hobbies, the number of teaching hours for ball teaching materials, selection of teaching materials, and theoretical teaching materials has increased significantly, and the flexibility and 
adaptability characteristics of local and national folk teaching contents have been given. This has completely changed the history of the past. Year-long national program, a national set of books. The influence of happy sports on the organization of physical education teaching is particularly prominent. Compared with the traditional forms of physical education teaching, happy sports do not require uniform, well-behaved, step-by-step, tangible and explicit forms, but through the use of musical techniques. In order to stimulate students' enthusiasm for learning and interest in learning, students can learn and play well in sports. Get tired of fear and better complete your learning tasks. Happy Sports also attaches great importance to the implicit effect of the teacher-student relationship on teaching effectiveness. It has consistently advocated that a good teacher-student relationship is an important prerequisite for good teaching results. It also emphasizes that in the course of physical education teaching, students must be highly regarded as the main body of the student. The role of the teacher is to respect the student's personality. To care for and protect every student, we must not only have the consciousness to lead the classroom, but also have the consciousness to serve the students. They can practice in ideas, words and deeds, style, character, and habits. For the example, with students suffering, fun, and activities, in order to exert imperceptible influence of physical education, increase the affinity and cohesion between teachers and students, and truly build a democratic, equal, harmonious and cooperative teacher-student relationship.

\section{Optimization of Physical Education Teaching Mode}

With the development of physical education teaching theory and practice, the research of physical education teaching mode is also deepening. The physical education teaching mode presents a pluralism phenomenon, which mainly includes sports skill teaching model, mental cultivation teaching model, emotional sense teaching model, sports Training teaching mode etc. In the application of physical education teaching model, it is influenced and restricted by many factors. Therefore, optimizing the physical education teaching model should consider the following basic issues.

The idea of physical education teaching is the soul of formulating the physical education teaching mode. The physical education teaching idea gives the vitality of the teaching mode and makes the teaching mode have a clear direction. However, due to the diversification of teaching ideas, the selection of teaching content also reflects the characteristics of diversity and complexity. In order to make the teaching thoughts organized and clarified and conformed to the school sports guiding ideology, we should focus on embodying the concept of "health first", lifelong sports, and happy sports. On this basis, different sports teaching should be selected according to the teaching content. Models, such as the development of physical fitness for students, the development of physical fitness, can use the active teaching mode, self-training teaching mode; in order to master the motor skills can use imitation teaching mode, program-based teaching mode; in order to promote the development of personality, you can use scene-style Teaching mode, heuristic teaching mode; In order to develop students' emotional experience, successful teaching mode and small group teaching mode can be adopted.

The physical education model that teachers choose to use must be compatible with the students' ability to accept. For students, according to different age groups, they can be divided into elementary school, middle school (junior high school, high school), and university. Because there are students in each stage Physiological and psychological differences should be taught in accordance with their aptitude and should be adapted to teaching ideas. For example, primary schools should focus on games, choose happy sports mode, scenario teaching mode, successful sports mode, and lifestyle sports mode; In the best period of learning sports technology, students have a certain interest in sports programs, and have certain abstract thinking skills. They choose heuristic teaching models, developmental teaching models, sports skill models, etc., and special teaching and training at the university level. Mainly, strengthen the skills training associated with the lifelong sports program, select skills teaching mode, physical training teaching mode.

Any physical education model must be used by teachers, and it can only be used under specific teaching conditions. The teaching conditions mainly refer to venues, equipment, time, projects, etc. 
Different physical education modes have specific conditions and scopes for their application. There are certain limitations in teaching goals. There is no universally effective teaching model for any specific teaching process. Because teachers have different abilities in using physical education teaching methods and conditions, the resulting teaching effects are different. Therefore, physical education teachers should be based on specific The goal of physical education teaching requires the rational use and combination of physical education teaching conditions so that the teaching model produces the best teaching effect. Each teacher has differences in his academic record, knowledge structure, ability level, teaching style, and so on, so he chooses physical education. In the model, the most appropriate teaching model should be selected from a multitude of teaching modes according to their own actual conditions; secondly, they must keep up with the teaching reform situation and needs, learn more, practice more, master multiple physical education modes, and learn to choose With the use of teaching methods; in addition, the structure of physical education teaching mode is not Unchanged, with the development of sports teaching mode teaching theory and practice and continuous improvement, teachers should combine their practical teaching creativity and personal style of play, and form their own teaching style.

\section{Conclusion}

Under the condition of comprehensively promoting quality education, the mode of physical education teaching presents a diversified trend. The physical education model should be based on "health first", lifelong sports, happy sports as the basic guiding ideology, and based on factors such as student characteristics, teaching conditions, and teacher level. Optimize physical education, eliminate traditional physical training teaching mode, promote physical education mode related to intelligent development, emotional experience, personality training, etc., fully mobilize students' enthusiasm and initiative, enable students to learn sports skills, and master lifelong physical education. Sports skills to promote the physical and mental health of students to meet the quality of education requirements.

\section{References}

[1] Luo Yongyi, Chou Jun. Reflection on the "Happy Sports" Teaching Idea Based on Sports Ontology [J]. Journal of Beijing Sport University. 2015(02)

[2] He Qiang, Xiong Xiaozheng. A New Understanding of "Happy Sports" [J]. Journal of Wuhan Institute of Physical Education. 2015(04)

[3] Wang Shuiquan, Mao Zhenming. The Source of "Happy Sports Theory" [J]. Sports and Science. 2014(02)

[4] Zhang Yahong. Practical Exploration of Interesting Track and Field Teaching Methods[J]. Chinese School Education. 2009(S2)

[5] Lei Jihong, Jia Jinshe. Status Quo and Development Trend of College Physical Education Models in China [J]. Journal of Xi'an Institute of Physical Education. 2006 (03)

[6] Mao Zhenming. Research on the Teaching Mode of Physical Education [J]. Journal of Guangzhou Institute of Physical Education. 2000(04) 